\title{
A stroking device for spatially separated couples
}

\author{
Elisabeth Eichhorn \\ Potsdam University of Applied Sciences \\ Faculty of Design \\ Pappelallee 8-9 \\ 14469 Potsdam, Germany \\ elisabeth.eichhorn@fh-potsdam.de
}

\author{
Reto Wettach \\ Potsdam University of Applied Sciences \\ Faculty of Design \\ Pappelallee 8-9 \\ 14469 Potsdam, Germany \\ wettach@fh-potsdam.de
}

\author{
Eva Hornecker \\ The Open University \\ Pervasive Interaction Lab \\ The Faculty of Mathematics, \\ Computing and Technology \\ Milton Keynes, MK7 6AA,UK \\ eva@ehornecker.de
}

\begin{abstract}
In this paper we present a device to support the communication of couples in long-distance relationships. While a synchronous exchange of factual information over distance is supported by telephone, e-mail and chat-systems, the transmission of nonverbal aspects of communication is still unsatisfactory. Videocalls let us see the partners' facial expression in real time. However, to experience a more intimate conversation physical closeness is needed. Stroking while holding hands is a special and emotional gesture for couples. Hence, we developed a device that enables couples to exchange the physical gesture of stroking regardless of distance and location. The device allows both sending and receiving. A user test supported our concept and provided new insights for future development.
\end{abstract}

\section{Categories and Subject Descriptors}

H.5.2 [User Interfaces]: Haptic I/O, H.5.3 [Group and

Organization Interfaces]: Synchronous interaction.

\section{General Terms}

Design, Experimentation, Human Factors

\section{Keywords}

tangible interface, force-feedback, physical presence, intimacy, mobile

\section{INTRODUCTION}

"Successful communication, verbal as well as non-verbal (gestures, facial expression etc.), is of outstanding importance within a partnership in general and especially within a longdistance partnership." [1]

The above statement from a partnership advisor summarises the origins of our intentions for the project. Due to the physical absence of the partner couples in long-distance relationships miss

Permission to make digital or hard copies of all or part of this work for personal or classroom use is granted without fee provided that copies are not made or distributed for profit or commercial advantage and that copies bear this notice and the full citation on the first page. To copy otherwise, or republish, to post on servers or to redistribute to lists, requires prior specific permission and/or a fee.

MobileHCI 2008, September 2-5, 2008, Amsterdam, the Netherlands.

Copyright (C) 2008 ACM 978-1-59593-952-4/08/09...\$5.00. tactile gestures as a part of non-verbal communication. A special tactile gesture for a couple is holding hands and stroking the partner's hand meanwhile. Depending on the context this gesture can be supporting, encouraging, loving, express joy and anger.

With our project we want to support the couples' non-verbal communication by providing a possibility to exchange stroking gestures. Therefore both partners receive a device, small enough to be held in one hand with which they can give and receive a stroking-impression at the same time.

\section{DETAILED DESCRIPTION}

\subsection{Background}

Loosing the opportunity of non-verbal communication and bodily contact in general is a serious problem for couples in longdistance relationships. This is a particular issue during emotionally intensive moments. For instance, comforting the other, which is usually to some extent physically expressed either replacing or adding to verbal exchange, becomes problematic. Feeling the partner's support in a physical way and beeing able to communicate non-verbally with him/her sustains intimacy between a couple. In this context stroking and caressing is an important gesture reserved to close persons.

Therefore, we decided to design a device to allow the exchange of stroking gestures over a distance. We believe that this device will enrich the couples' communication which is currently limited to phone, video-call or text and create a much more intimate conversation.

We were encouraged by the project „Communicating Intimacy One Bit at a Time" [2] which found that even a minimal nonphysical exchange of non-verbal gestures (meaning „I think of you" for example) is already valuable for the partners.

\subsection{The Design}

The couple is given the following set-up:

Each partner has a device, sized to fit nicely in one hand. Holding the device, they are now able to stroke and with the same device receive the actions the partner performs to his/her own device.

In the process of designing the device, two variations of the basic concept were considered: The device can be used to touch each other's hands, but also to touch the partner on other parts of the body. To test both variations we built two different prototypes. Prototype A (see figure 1) was modeled according to the form and function of the hand, and therefore has a very organic shape. In contrast, prototype B (figure 2) is modeled in a more abstract 
manner, similar to a cuboid. This was done to not force it into the hand so much but also to other parts of the body. Furthermore, there are various forms for the input. Prototype A receives input by stroking with your thumb over a certain area, very similar to when holding hands. On B, again more abstract, you turn a little knob in a circular path, similar to stroking the partner with just one finger. The knob is under the fabric so the turning is a smooth move.

The output for A and B is created by a small arm powered by a miniature servo motor, which turns the arm in circular movements. The arm is coverd by the textile the prototypes are covered with. This creates a comfortable feeling similar to a stroke of your partners thumb in the palm of your hand. The difference is that $\mathrm{A}$ has only one arm (of about $1 \mathrm{~cm}$ length) and $\mathrm{B}$ has a cross of four arms (each of about $1 \mathrm{~cm}$ length) that create a more intense movement under the textile.

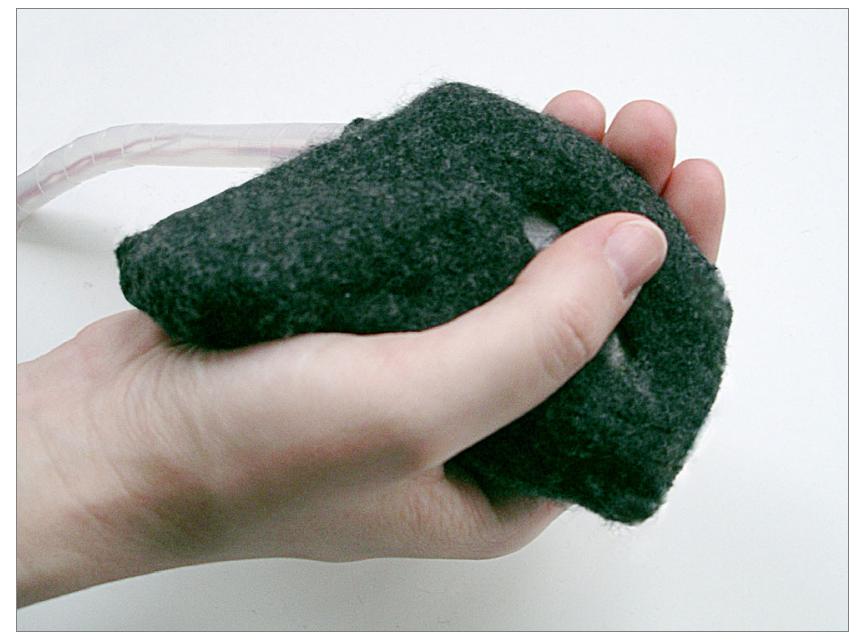

Figure 1: Prototype A: The input area is currently under the thumb, the output in the hands palm.

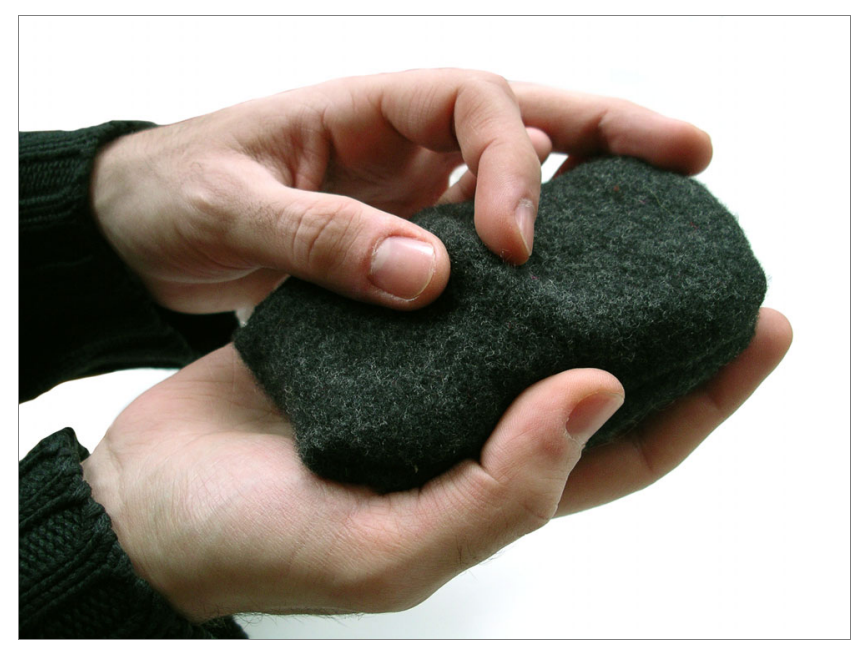

Figure 2: Prototype B: The input is the knob under the textile, the output is in the palm of the hand.

As stroking is a very intimate gesture, our desire was to create a device, looking both discreet and private. Therefore we have chosen a soft textile with a muted colour.

\subsection{Prototypes}

Prototype A was realized with a lightweight modelling clay (see figure 3) covered with a cotton fabric. The input area is a self made, linear, flat potentiometer. At this early stage, an electrical contact was required to detect the position of the user's thumb on the potentiometer. It is established through a wire attached to a glove that participants wear (see figure 4). The position of the thumb at the potentiometer is associated to the position of the output arm. Future prototypes will employ industrial, flat potentiometers, which response directly to the users' fingers. The output is created by an embedded servo motor that moves the arm as described above.

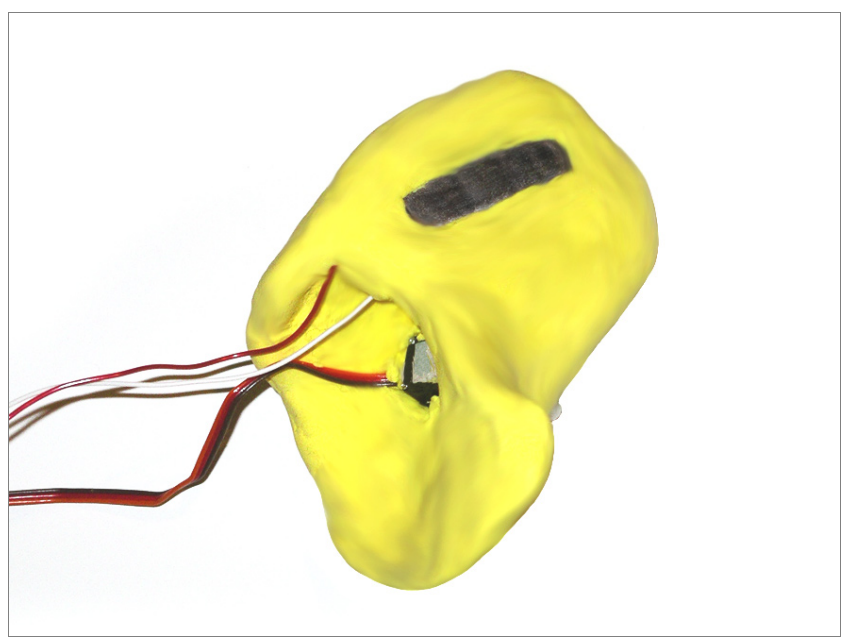

Figure 3: Prototype A without fabric cover: The input area on top, the servo that creates the output embedded.

B is realized with a foam material bolstered up with cardboard and covered with the same cotton fabric as A. The input is received by an embedded pre-set potentiometer to which a knob is mounted. The output is provided the same way as in A.

Both prototypes exchange data via an arduino board [3] both are wired to. For a real product the devices would be connected wireless to the users' cell phones (e.g. over Bluetooth) and the data would be exchanged via the cell phones. This requires the device to be powered by batteries, and requires a design that allows replacing batteries.

\section{EVALUATION}

Evaluation took place in three sessions. The first session was a group session with two couples and one man. The second and third session each involved one couple. All together this involved nine people, including one couple living together with one partner traveling a lot, three couples living spatially separated and the individual man of the group session who is living in a longdistance relationship. The participants' age varied form 21 to 57 years. Professions varied widely from engineer to travel agent and teacher.

We think of our device to be used predominantly in a private environment and in addition to telephone or even videocall conversations. Therefore we wanted the test to take place in an atmosphere similar to a likely usage setting. Thus, we tested the device at people's homes and the participants could see and hear 
each other (group session participants were familiar with the hosts' home). First the participants were made aware of their phases of spatial separation and then introduced to our concept of transmitting physical gestures over a distance to support communication. Then they were handed the prototypes and encouraged to think aloud while using them. Every participant tried out both prototypes always with a/his/her partner. For this first user test, both partners were in the same room, allowing visual and auditory communication as in the envisioned use scenario, but of higher quality than standard video conferencing would offer. In our initial study the focus was on how the devices themselves were perceived, justifying this simplified setup. For a further user study, we would set up a video link between two rooms in order to assess the added value of the tactile communication channel for participant's experience of intimacy.

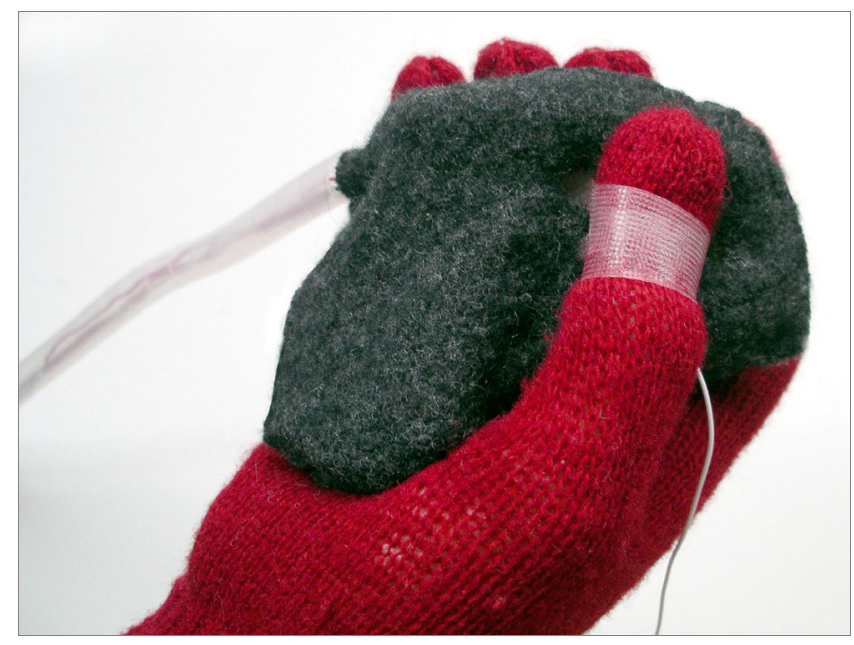

Figure 4: Prototype A with glove.

In the final stage everyone was questioned about the different prototypes and how valuable such a device would be for them. All participants valued the possibility to transmit a tactile gesture as a 4 or a 5 on a likert scale from 1 ("useless") to 5 ("very useful"). All participants preferred prototype A over B. Reasons for this were:

- the ergonomic shape that fitted well into the hand

- the input was considered more natural and elegant, only one person liked the more abstract input of prototype B better

- the output was more gentle and thus closer to a real caress

- two participants guessed that they felt extra comfortable with prototype A due to the snugly feeling from the glove

Despite of this some participants liked the idea of B to be placed anywhere on the body.

Seven out of nine participants wished to have more input options and linked with that more outputs. Associated to this was the critique that:

- the gesture could involve more parts of the hand (for in- and output) to give the impression of using more than one finger - the pressure should be variable

Suggestions from the participants for further fields of application included to use the device to stay in physical contact to somebody lying in coma.

\section{RELATED WORK}

Probably the best-known example for transmitting tactile gestures is "inTouch" from MIT Media Lab [4]. The users have three logs they can twist or stop to interact with. Due to its advanced implementation and the chosen kind of action it supports playful use. Contrary to this playful interaction we wanted to concentrate on the meaning of stroking as an additional communication form. We think that with our approach of designing a strokingimpression it is more meaningful to the users than just giving a twist to a $\log$.

Another related project is "Tug n' Talk: A Belt Buckle for Tangible Tugging Communication" [5]. Both communication partners are wearing a belt with two cords attached. One of them is fixed to the wearer's t-shirt, this is the partner's output. The second one is his/her own input. Thus if one partner pulls his/her cord the other partner gets tugged at his shirt like little children do. This is a good example of observing the gestures people carry out to achieve attention. In the same way we choose the input option for our project.

A third project is "The Hug" [6]. Its creators developed an interface that encourages physical contact with itself (an organic form, sized to be hugged like a pillow). To activate communication via telephone you have to press certain parts and it can transfer light and sound signals as well as vibrate. What is interesting for us is the design that invites to physical contact and may create a more intimate atmosphere while calling your loved ones. Also we wanted to explore a way to transmit physical gestures between partners.

This is also the approach of the "Hug Shirt", developed by CuteCircuit [7]. The "Hug Shirt" is a shirt equipped with sensors and actuators in selected areas. By touching these areas, partners can exchange a hug. This advanced implementation encourages us though we want our device to be more flexible. First we don't want to define the areas of the body that can receive stroking and second we want to give users more differentiated input options.

\section{CONCLUSION}

With our project we presented a way to enrich the communication between spatially separated couples with non-verbal gestures. We decided to concentrate on stroking cause we found this to be a physical gesture reserved for your loved ones which makes it very meaningful.

The user test provided very encouraging feedback on the different prototypes as well as to the concept itself. As the test participants liked the organic feeling, but also the possibility to place the device wherever you want (on the cheek for example) we will work on combining the two approaches from our prototypes A and $\mathrm{B}$.

Next steps include finding an organic shape that fits well into a hand as well as on other body parts. For this, we perform modeling studies at the moment. As, so far, partners can only perform one kind of gesture a more complex system of "touch areas" and connected servo drives is to be developed in order to support a more individual gesture exchange. We also think about additional kinds of input and output: a two- or even threedimensional stroking facility for the input. Output could be 
extended by piezoelectric elements that can cause a very subtle impression for the receiving partner.

\section{ACKNOWLEDGMENTS}

We like to thank Johannes Landstorfer from the masters course of the Potsdam University of Applied Sciences for his advice during the process. Also we like to thank the participants of our user test for their openness to give us an insight into their private lives.

\section{REFERENCES}

[1] Wendl, P. (2007) Fern-Beziehung!?. http://www.gelingendefernbeziehung.de/pageID_1861484.html, Last accessed: $27.01 .200 \overline{8}$, (authors translation)

[2] Kaye, J., Levitt, M. K., Nevins, J., Golden, J. and Schmidt, V. (2005). Communicating Intimacy One Bit at a Time. Proc. of CHI'05 Extended Abstracts, ACM Press, N.Y., pp 1529-1532.
[3] Arduino Physical Computing Platform; http://www.arduino.cc, Last accessed: 27.01.2008

[4] Brave, S., Dahley, A. (1997): inTouch: A Medium for Haptic Interpersonal Communication. Proc. of CHI'97 extended abstracts. ACM Press, N.Y., pp. $363-364$

[5] Adcock, M., Harry, D., Boch, M., Poblano, R.-D. and Harden, V. Tug n' Talk: A Belt Buckle for Tangible Tugging Communication. Presented at alt.chi 2007, http://www.media.mit.edu/ dharry/tugandtalk/ tugandtalk_FINAL.pdf

[6] Gemperle, F., DiSalvo, C., Forlizzi J., and Yonkers, W. (2003): The Hug: a new form for communication. Proceedings of DUX 2003 (Designing for user experiences), ACM Press, N.Y., pp: $1-4$

[7] Rosella, F., Genz, R., CuteCircuit, 2005-2007, http://www.cutecircuit.com/now/projects/wearables/frhugs, Last accessed: 27.01.2008 